\title{
Twenty Five Years of Drug Discovery at the University of California Targeting Kinetoplastid Parasites
}

\author{
McKerrow $\mathrm{JH}^{*}$, Siqueira-Neto JL, McCall L-I and Otrubova K
}

Skaggs School of Pharmacy and Pharmaceutical Sciences, University of California, San Diego, Center for Discovery and Innovation in Parasitic Diseases, USA

${ }^{*}$ Corresponding author: McKerrow JH, Skaggs School of Pharmacy and Pharmaceutical Sciences, University of California, San Diego, Center for Discovery and Innovation in Parasitic Diseases, USA, E-mail: jmckerrow@ ucsd.edu

Citation: McKerrow JH, Siqueira-Neto JL, McCall L-I, Otrubova K (2016) Twenty Five Years of Drug Discovery at the University of California Targeting Kinetoplastid Parasites. J Pharm Drug Devel 4(1): 101. doi: 10.15744/2348-9782.4.101

Received Date: August 19, 2016 Accepted Date: October 06, 2016 Published Date: October 07, 2016

\begin{abstract}
This review summarizes 25 years of screening compounds against three major kinetoplastid parasites, Trypanosoma brucei, Trypanosoma cruzi, and Leishmania spp. The work was carried out at two University of California campuses by a consortium of scientists. The history of this effort is summarized beginning with DARPA and NIAID TDRU projects. The compound collections that were screened came from both academic and industry sources. To facilitate screening, high throughput or high content microtiter plate-based assays were developed. Three approaches to discovery of new drugs for kinetoplastid diseases are presented. These include structure-based drug design against specific parasite molecular targets, repurposing of already approved drugs, and screening of marine natural products. As similar screening efforts against other molecular targets or with other compound libraries are ongoing, one conclusion is that the current bottleneck in drug development for neglected tropical diseases is downstream of compound screening and hit to lead. More medicinal chemistry efforts for lead optimization and more preclinical package work needs to be done. For more information see (www. cdipd.org).
\end{abstract}

Keywords: Drug Discovery; Knetoplastid parasites; Trypansoma brucei; Trypanosoma cruzi; Leishmania spp

\section{Background}

The three major kinetoplastid parasites are Trypansoma brucei, Trypanosoma cruzi, and Leishmania spp. These pathogens are responsible for human African trypanosomiais (HAT) also known as Sleeping Sickness, Chagas Disease, and cutaneous or visceral leishmaniasis. These are designated "neglected tropical diseases" (NTDs) because they primarily affect poor people in poor regions of the world. Therefore there is little or no economic incentive for the pharmaceutical industry to develop new drugs, vaccines, or diagnostics. Over the past 25 years, a consortium of scientists at two University of California campuses have screened, optimized and advanced compounds obtained from both academic and industry sources to identify new therapies for kinetoplastid diseases. This review will summarize the history of this effort, its current status, and suggestions for future development.

\section{History}

Work at the University of California San Francisco began in the late 1980's and early 1990's supported by DARPA (Defense Advanced Research Projects Agency) and a Tropical Disease Research Unit program project grant from the NIAID (National Institute of Allergy and Infectious Diseases). The DARPA project was led by computational biologist Fred Cohen. It focused on the development of computational approaches to drug discovery and design following up on the pioneering molecular design work of Irwin "Tack" Kuntz. While the original focus of the DARPA project was on other tropical diseases (malaria and schistosomiasis), the compounds produced were cross-screened against kinetoplastids [1-4].

The original research on Trypanosoma cruzi and Chagas Disease at UCSF was supported by the Tropical Disease Research Unit grant. The first report identifying an inhibitor of the major protease of Trypanosoma cruzi as a drug lead was published in 1993 [5]. Research over the succeeding two decades was primarily supported by funding from the NIAID, the Sandler Family Foundation, and most recently the European Union (Kindred, FP7). Supplemental funding came from the American Heart Association, the World Health Organization, DNDi (Drugs for Neglected Diseases Initiative), the Department of Veterans Affairs, and the Burroughs Wellcome Fund. As detailed in the References, this funding supported assay development, structure-based drug design, HTS, and HCS. In 2014, much of the kinetoplastid drug discovery research shifted from UCSF to the University of California San 
Diego (UCSD). Drug discovery research continued at the UCSD site with addition of new HTS and HCS screens (www.cdipd.org). Furthermore a Drug Development Pipeline was launched (http://cddi.ucsd.edu/resources/drug-pipeline.html) that provides the pre-clinical package of assays required to move a compound "hit" to a clinical candidate. This is the key for NTD drug development that must usually be done without support from an industry partner.

The compound collections ("libraries") that were screened against the three kinetoplastid parasites came from both academic and industry sources. Over 20 companies donated compounds to be tested. Transfer and testing was carried out through material transfer agreements (MTAs). To facilitate screening, high throughput or high content microtiter plate-based assays were developed [6-8]. These were compatible with robotic liquid handling and automated imaging equipment.

\section{Results}

A summary of the approximate number of compounds screened, and how far they progressed, is given in Figures 1, 2, 3 and 4. A more comprehensive review of all the compound series tested can be found in the over 70 publications that resulted from this work as listed in References [1-70].

\section{Notable molecular targets}

Both phenotypic screens (against the parasites themselves) as well as screens against specific molecular targets were carried out. Phenotypic screens have the advantage of identifying hits directly against the relevant parasite stage [6-8]. Target-based screens have more capacity and are more focused. That is they can use inhibitor libraries that might have been produced and validated against homologous enzyme or receptor targets. The molecular targets screened against at the two UC campuses were by no means comprehensive, but rather reflected the research interests of collaborators and whether they had been shown to be "druggable". "Druggable" targets are herein defined as proteins (usually enzymes) which have homologues (usually human) successfully targeted by approved drugs in current clinical use. Two notable molecular targets in Figures 1, 2, 3 and 4 are proteases [29,38,48,66] and sterol biosynthesis enzymes [60,61] both of which represent drug target families for which multiple drugs are in clinical use. In some cases compounds were de-prioritized for PK/PD reasons but helped identify new targets like cytochrome b [67,68].

From phenotypic screens the most advanced hit was an oxyborole from Anacor Pharmaceuticals that is now in clinical trials for HAT. SCYX-7158 was identified as a promising hit by Zachary Mackey in the original HTS assay [6] and subsequently optimized at Scynexis for blood-brain barrier penetration [49].

\section{Chagas' Disease \\ Drug Development Pipeline (part 1) \\ C)ㅁIPD:}

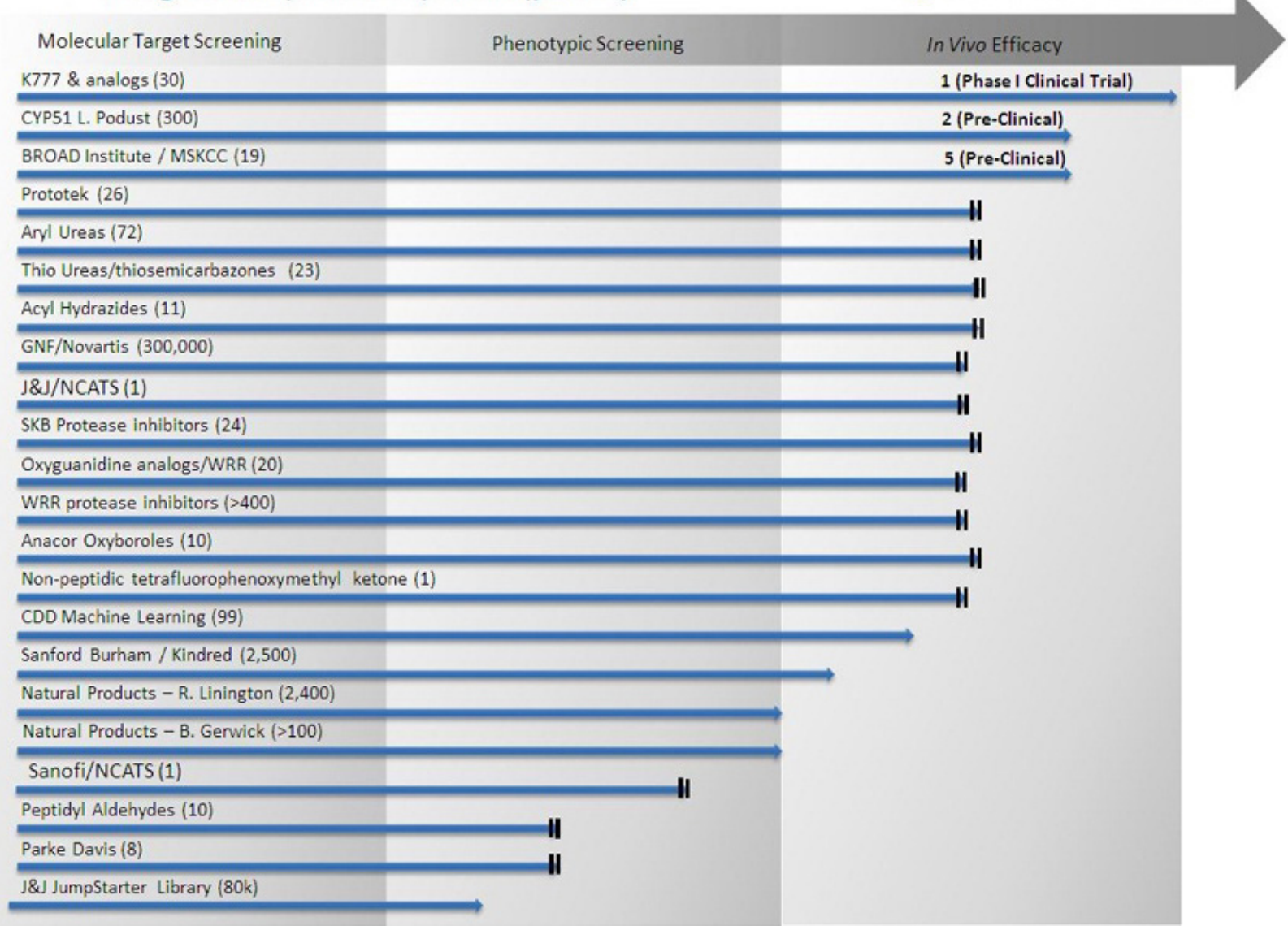




\section{Chagas' Disease \\ Drug Development Pipeline (part 2)}

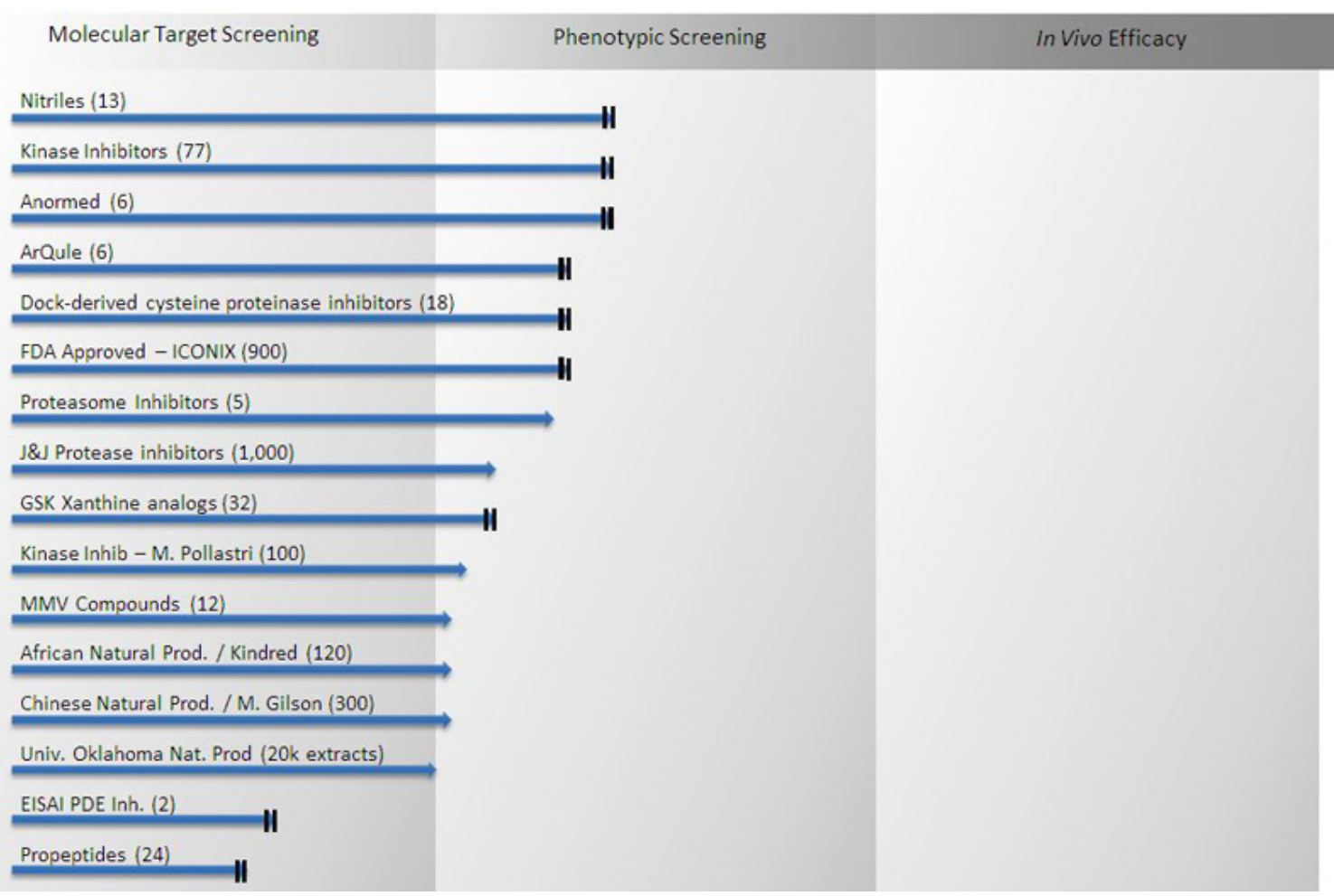

Figure 1: "Screening Molecular Target" refers to those compounds with known molecular target so the first HTS screen was against the target itself (Eg: kinases, proteases)

Leishmaniasis

Drug Development Pipeline
RCDIPD $=$

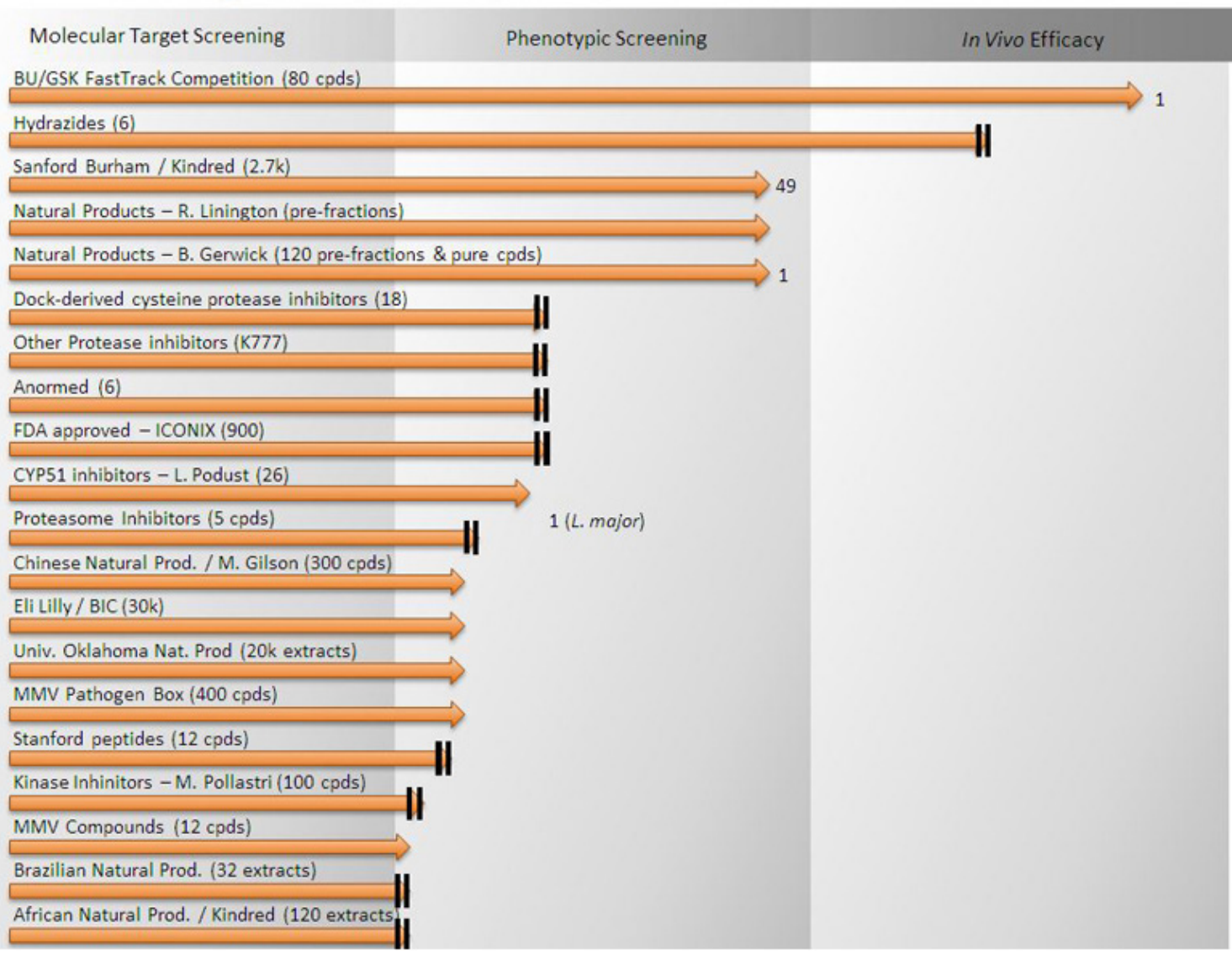

Figure 2: Chemical class is given for each compound library except in some cases where compounds from companies were not disclosed for IP reasons 
Human African Trypanosomiasis

Drug Development Pipeline (part 1)

C)CDIPD= Molecular Target Screening

Anacor Oxyboroles (133) In Vivo Efficacy

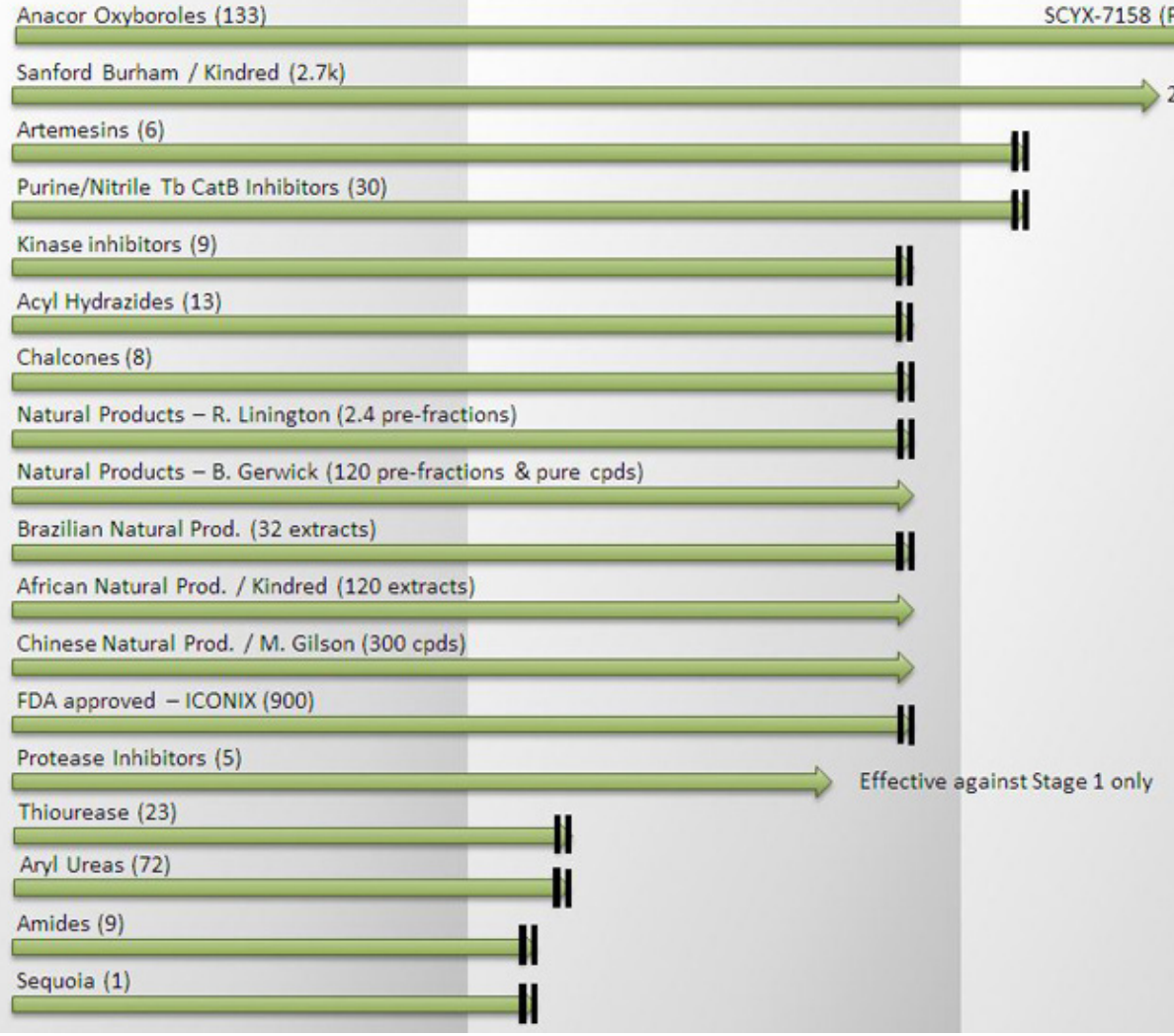

Figure 3: "Phenotypic Screening" refers to testing against the parasites themselves

\section{Human African Trypanosomiasis}

Drug Development Pipeline (part 2)

\section{R)CDIPD=}

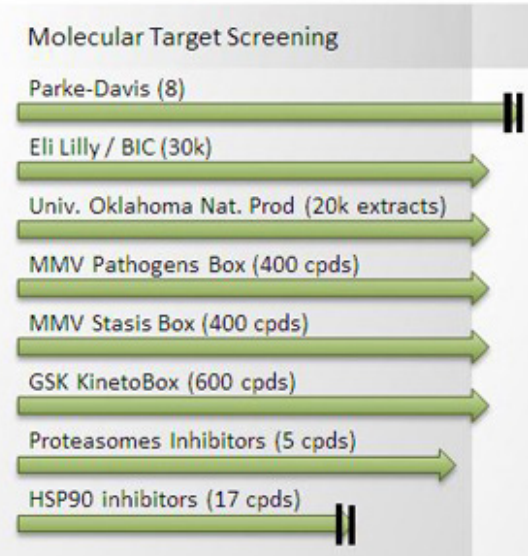

Phenotypic Screening

In Vivo Efficacy

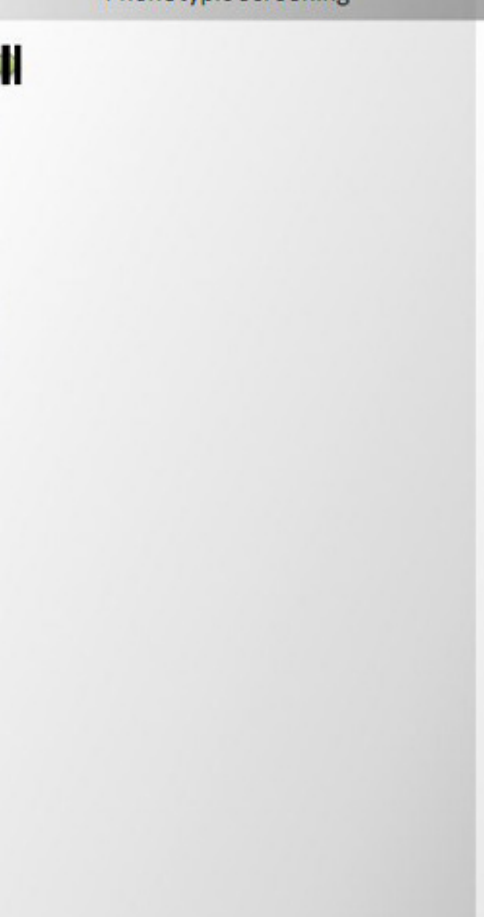

Figure 4: "Phenotypic Screening" refers to testing against the parasites themselves 
Figures show numbers of compounds tested and how far they progressed for each of the three kinetoplastids assayed.

Double bars indicate that a program was stopped because of lack of efficacy at that stage of screening or issues with ADME, toxicity, or pharmacokinetics.

Arrow heads indicate programs still in progress.

When available and relevant, Reference numbers are given in brackets [ ]

Other promising phenotypic screen hits included compounds from Collaborative Drug Design [65] and the Memorial Sloan Kettering Cancer Center (manuscript in preparation).

\section{Repurposed drugs}

One potentially promising and cost effective approach to identifying drugs for NTDs is "repurposing" drugs already approved and in clinical use targeting other diseases (ncats.nih/preclinical/repurpose). Through the efforts of Teri Melese, a 900 compound library was donated in 2009 by ICONIX to James McKerrow. This library was screened $[7,8]$ and later increased in size to include all FDA approved drugs with consultation by Michele Arkin of the UCSF SMDC (www.smdc.ucsf.edu), and support from the Bill and Melinda Gates Foundation. A second library of 2700 compounds, including some still in clinical trials, was recently obtained from the Prebys Sanford Burnham Institute. While a promising clinical candidate for amebiasis and filarid worm diseases was identified in these libraries, no promising drug candidate was identified for kinetoplastid diseases.

\section{Marine Natural Products}

One of the most promising sources of potential drugs is marine natural products provided by several laboratories. Natural products are the origin of $60 \%$ of drugs approved by the FDA. Most of the antibiotics now used for bacterial infections are natural products. But industry has until recently abandoned natural product development for reasons of complex synthesis challenges and scale-up issues. These issues have been addressed with new technology in HPLC, mass spectrometry, and genome sequencing. As Figures 1, 2, 3 and 4 indicate, several marine natural products are still being evaluated and represent some of the most effective "hits" to date $[51,53]$. In some cases the parasite molecular target of a specific marine natural product is now known $[58,59]$.

\section{Conclusion}

Twenty five years of drugs screening has resulted in the incorporation of new HTS technology for assays involving both specific protein targets as well as kinetoplastid parasites themselves [1-70]. Molecular targets and natural products have yielded a higher hit rate than small synthetic molecule libraries. Many laboratories around the world are now carrying out similar screens with other molecular targets and other compound libraries. The bottleneck in drug development for NTDs is therefore "downstream" of screening. More medicinal chemistry help is needed for lead optimization and more compounds need to be pushed through the pre-clinical pipeline steps.

\section{References}

1. Troeberg L, Chen X, Flaherty TM, Morty RE, Cheng M, et al. (2000) Chalcone, acyl hydrazide, and related amides kill cultured Trypanosoma brucei brucei. Mol Med 6: 660-9.

2. Du X, Hansell E, Engel JC, Caffrey CR, Cohen FE, et al. (2000) Aryl ureas represent a new class of anti-trypanosomal agents. Chem Biol 7: 733-42.

3. Rodrigues CR, Flaherty TM, Springer C, McKerrow JH, Cohen FE (2002) CoMFA and HQSAR of acylhydrazide cruzain inhibitors. Bioorg Med Chem Lett 12: 1537-41.

4. Du X, Guo C, Hansell E, Doyle PS, Caffrey CR, et al. (2002) Synthesis and structure-activity relationship study of potent trypanocidal thio semicarbazone inhibitors of the trypanosomal cysteine protease cruzain. J Med Chem 45: 2695-707.

5. Harth G, Andrews N, Mills AA, Engel JC, Smith R, et al. (1993) Peptide-fluoromethyl ketones arrest intracellular replication and intercellular transmission of Trypanosoma cruzi. Mol Biochem Parasitol 58: 17-24.

6. Mackey ZB, Baca AM, Mallari JP, Apsel B, Shelat A, et al. (2006) Discovery of trypanocidal compounds by whole cell HTS of Trypanosoma brucei. Chem Biol Drug Des 67: 355-63.

7. Engel JC, Ang KK, Chen S, Arkin MR, McKerrow JH, et al. (2010) Image-based high-throughput drug screening targeting the intracellular stage of Trypanosoma cruzi, the agent of Chagas' disease. Antimicrob Agents Chemother 54: 3326-34.

8. De Muylder G, Ang KK, Chen S, Arkin MR, Engel JC, et al. (2011) A screen against Leishmania intracellular amastigotes: comparison to a promastigote screen and identification of a host cell-specific hit. PLoS Negl Trop Dis 5: e1253.

9. Selzer PM, Chen X, Chan VJ, Cheng M, Kenyon GL, et al. (1997) Leishmania major: molecular modeling of cysteine proteases and prediction of new nonpeptide inhibitors. Exp Parasitol 87: 212-21.

10. Engel JC, Doyle PS, Palmer J, Hsieh I, Bainton DF, et al. (1998) Cysteine protease inhibitors alter Golgi complex ultrastructure and function in Trypanosoma cruzi. J Cell Sci 111: 597-606

11. Engel JC, Doyle PS, Hsieh I, McKerrow JH (1998) Cysteine protease inhibitors cure an experimental Trypanosoma cruzi infection. J Exp Med 188: 725-34.

12. Scheidt KA, Roush WR, McKerrow JH, Selzer PM, Hansell E, et al. (1998) Structure-based design, synthesis and evaluation of conformationally constrained cysteine protease inhibitors. Bioorg Med Chem 6: 2477-94.

13. McKerrow JH (1999) Development of cysteine protease inhibitors as chemotherapy for parasitic diseases: insights on safety, target validation, and mechanism of action. Int J Parasitol 29: 833-7. 
14. Selzer PM, Pingel S, Hsieh I, Ugele B, Chan VJ, et al. (1999) Cysteine protease inhibitors as chemotherapy: lessons from a parasite target. Proc Natl Acad Sci U S A 96: 11015-22.

15. Troeberg L, Morty RE, Pike RN, Lonsdale-Eccles JD, Palmer JT, et al. (1999) Cysteine proteinase inhibitors kill cultured bloodstream forms of Trypanosoma brucei brucei. Exp Parasitol 91: 349-55.

16. Brinen LS, Hansell E, Cheng J, Roush WR, McKerrow JH, et al. (2000) A target within the target: probing cruzain's P1' site to define structural determinants for the Chagas' disease protease. Structure 8: 831-40.

17. Hernandez AA, Roush WR (2002) Recent advances in the synthesis, design and selection of cysteine protease inhibitors. Curr Opin Chem Biol 6: 459-65.

18. Lecaille F, Cotton J, McKerrow JH, Ferrer-Di Martino M, Boll-Bataille E, et al. (2001) Reversible inhibition of cathepsin L-like proteases by 4-mer pseudopeptides. FEBS Lett 507: 362-6.

19. Roush WR, Cheng J, Knapp-Reed B, Alvarez-Hernandez A, McKerrow JH, et al. (2001) Potent second generation vinyl sulfonamide inhibitors of the trypanosomal cysteine protease cruzain. Bioorg Med Chem Lett 11: 2759-62.

20. Caffrey CR, Schanz M, Nkemngu NJ, Brush M, Hansell E, et al. (2002) Screening of acyl hydrazide proteinase inhibitors for antiparasitic activity against Trypanosoma brucei. Int J Antimicrob Agents 19: 227-31.

21. Nkemgu NJ, Grande R, Hansell E, McKerrow JH, Caffrey CR, et al. (2003) Improved trypanocidal activities of cathepsin L inhibitors. Int J Antimicrob Agents 22: $155-9$.

22. Chiyanzu I, Hansell E, Gut J, Rosenthal PJ, McKerrow JH, et al. (2003) Synthesis and evaluation of isatins and thiosemicarbazone derivatives against cruzain, falcipain-2 and rhodesain. Bioorg Med Chem Lett 13: 3527-30.

23. Greenbaum DC, Mackey Z, Hansell E, Doyle P, Gut J, et al. (2004) Synthesis and structure-activity relationships of parasiticidal thiosemicarbazone cysteine protease inhibitors against Plasmodium falciparum, Trypanosoma brucei, and Trypanosoma cruzi. J Med Chem 47: 3212-9.

24. Fujii N, Mallari JP, Hansell EJ, Mackey Z, Doyle P, et al. (2005) Discovery of potent thiosemicarbazone inhibitors of rhodesain and cruzain. Bioorg Med Chem Lett 15: 121-3.

25. Barr SC, Warner KL, Kornreic BG, Piscitelli J, Wolfe A, et al. (2005) A cysteine protease inhibitor protects dogs from cardiac damage during infection by Trypanosoma cruzi. Antimicrob Agents Chemother 49: 5160-1.

26. Vicik R, Hoerr V, Glaser M, Schultheis M, Hansell E, et al. (2006) Aziridine-2,3-dicarboxylate inhibitors targeting the major cysteine protease of Trypanosoma brucei as lead trypanocidal agents. Bioorg Med Chem Lett 16: 2753-7.

27. Rapp M, Haubrich TA, Perrault J, Mackey ZB, McKerrow JH, et al. (2006) Antitrypanosomal activity of 5'-deoxy-5'-(iodomethylene)adenosine and related 6-Ncyclopropyladenosine analogues. J Med Chem 49: 2096-102.

28. Caffrey CR, Steverding D, Swenerton RK, Kelly B, Walshe D, et al. (2007) Bis-acridines as lead antiparasitic agents: structure-activity analysis of a discrete compound library in vitro. Antimicrob Agents Chemother 51: 2164-72.

29. Doyle PS, Zhou YM, Engel JC, McKerrow JH (2007) A cysteine protease inhibitor cures Chagas' disease in an immunodeficient-mouse model of infection. Antimicrob Agents Chemother 51: 3932-9.

30. Mallari JP, Shelat AA, Obrien T, Caffrey CR, Kosinski A, et al. (2008) Development of potent purine-derived nitrile inhibitors of the trypanosomal protease TbcatB. J Medicinal Chem 51: 545-52.

31. Mallari JP, Shelat A, Kosinski A, Caffrey CR, Connelly M, et al. (2008) Discovery of trypanocidal thiosemicarbazone inhibitors of rhodesain and TbcatB. Bioorg Med Chem Lett 18: 2883-5.

32. Chen YT, Lira R, Hansell E, McKerrow JH, Roush WR (2008) Synthesis of macrocyclic trypanosomal cysteine protease inhibitors. Bioorg Med Chem Lett 18: $5860-3$.

33. Brak K, Doyle PS, McKerrow JH, Ellman JA (2008) Identification of a new class of nonpeptidic inhibitors of cruzain. J Am Chem Soc 130: 6404-10.

34. Jaishankar P, Hansell E, Zhao DM, Doyle PS, McKerrow JH, et al. (2008) Potency and selectivity of P2/P3-modified inhibitors of cysteine proteases from trypanosomes. Bioorg Med Chem Lett 18: 624-8.

35. Fricker SP, Mosi RM, Cameron BR, Baird I, Zhu Y, et al. (2008) Metal compounds for the treatment of parasitic diseases. J Inorg Biochem 102: 1839-45.

36. Johnson TA, Amagata T, Sashidhara KV, Oliver AG, Tenney K, et al. (2009) The aignopsanes, a new class of sesquiterpenes from selected chemotypes of the sponge Cacospongia mycofijiensis. Org Lett 11: 1975-8.

37. Chen CK, Doyle PS, Yermalitskaya LV, Mackey ZB, Ang KK, et al. (2009) Trypanosoma cruzi CYP51 inhibitor derived from a Mycobacterium tuberculosis screen hit. PLoS Negl Trop Dis 3: e372.

38. Kerr ID, Lee JH, Farady CJ, Marion R, Rickert M, et al. (2009) Vinyl sulfones as antiparasitic agents and a structural basis for drug design. J Biol Chem 284: 25697-703.

39. Mallari JP, Shelat AA, Kosinski A, Caffrey CR, Connelly M, et al. (2009) Structure-guided development of selective TbcatB inhibitors. J Med Chem 52: 6489-93. 40. Rubio BK, Tenney K, Ang KH, Abdulla M, Arkin M, et al. (2009) The marine sponge Diacarnus bismarckensis as a source of peroxiterpene inhibitors of Trypanosoma brucei, the causative agent of sleeping sickness. J Nat Prod 72: 218-22.

41. Watts KR, Ratnam J, Ang K-H, Tenney K, Compton JE, et al. (2010) Assessing the trypanocidal potential of natural and semi-synthetic diketopiperazines from two deep water marine-derived fungi. Bioorg Med Chem 18: 2566-74.

42. Brak K, Kerr ID, Barrett KT, Fuchi N, Debnath M, et al. (2010) Nonpeptidic tetrafluorophenoxymethyl ketone cruzain inhibitors as promising new leads for Chagas disease chemotherapy. J Med Che 53: 1763-73.

43. Mott BT, Ferreira RS, Simeonov A, Jadhav A, Ang KK, et al. (2010) Identification and optimization of inhibitors of Trypanosomal cysteine proteases: cruzain, rhodesain, and TbCatB. J Med Chem 53: 52-60.

44. Bryant C, Kerr ID, Debnath M, Ang KK, Ratnam J, et al. (2009) Novel non-peptidic vinylsulfones targeting the S2 and S3 subsites of parasite cysteine proteases. Bioorg Med Chem Lett 19: 6218-21.

45. Chen CK, Leung SS, Guilbert C, Jacobson MP, McKerrow JH, et al. (2010) Structural characterization of CYP51 from Trypanosoma cruzi and Trypanosoma brucei bound to the antifungal drugs posaconazole and fluconazole. PLoS Negl Trop Dis 4: e651.

46. Doyle PS, Chen CK, Johnston JB, Hopkins SD, Leung SS, et al. (2010) A nonazole CYP51 inhibitor cures Chagas' disease in a mouse model of acute infection. Antimicrob Agents Chemother 54: 2480-8. 
47. Hernandes MZ, Rabello MM, Leite AC, Cardoso MV, Moreira DR, et al. (2010) Studies toward the structural optimization of novel thiazolylhydrazone-based potent antitrypanosomal agents. Bioorg Med Chem 18: 7826-35.

48. Chen YT, Brinen LS, Kerr ID, Hansell E, Doyle PS, et al. (2010) In vitro and in vivo studies of the trypanocidal properties of WRR-483 against Trypanosoma cruzi. PLoS Negl Trop Dis 4: e825.

49. Ding D, Zhao Y, Meng Q, Xie D, Nare B, et al. (2010) Discovery of novel benzoxaborole-based potent antitrypanosomal agents. ACS Med Chem Lett 1: 165-9. 50. Ang KK, Ratnam J, Gut J, Legac J, Hansell E, et al. (2011) Mining a cathepsin inhibitor library for new antiparasitic drug leads. PLoS Negl Trop Dis 5: e1023.

51. Johnson TA, Sohn J, Inman WD, Estee SA, Loveridge ST, et al. (2011) Natural product libraries to accelerate the high-throughput discovery of therapeutic leads. J Nat Prod 74: 2545-55.

52. Lavrado J, Mackey Z, Hansell E, McKerrow JH, Paulo A, et al. (2012) Antitrypanosomal and cysteine protease inhibitory activities of alkyldiamine cryptolepine derivatives. Bioorg Med Chem Lett 22: 6256-60.

53. Navarro G, Chokpaiboon S, De Muylder G, Bray WM, Nisam SC, et al. (2012) Hit-to-lead development of the chamigrane endoperoxide merulin A for the treatment of African sleeping sickness. PLoS One 7: e46172.

54. dos Santos Filho JM, Moreira DR, de Simone CA, Ferreira RS, McKerrow JH, et al. (2012) Optimization of anti-Trypanosoma cruzi oxadiazoles leads to identification of compounds with efficacy in infected mice. Bioorg Med Chem 20: 6423-33.

55. Gunatilleke SS, Calvet CM, Johnston JB, Chen CK, Erenburg G, et al. (2012) Diverse inhibitor chemotypes targeting Trypanosoma cruzi CYP51. PLoS Negl Trop Dis 6: e1736.

56. Lee GM, Balouch E, Goetz DH, Lazic A, McKerrow JH, et al. (2012) Mapping inhibitor binding modes on an active cysteine protease via nuclear magnetic resonance spectroscopy. Biochemistry 51: 10087-98.

57. Mashiyama ST, Koupparis K, Caffrey CR, McKerrow JH, Babbitt PC (2012) A global comparison of the human and T. brucei degradomes gives insights about possible parasite drug targets. PLoS Negl Trop Dis 6: e1942.

58. Sanchez LM, Knudsen GM, Helbig C, De Muylder G, Mascuch SM, et al. (2013) Examination of the mode of action of the almiramide family of natural products against the kinetoplastid parasite Trypanosoma brucei. J Nat Prod 76: 630-41.

59. Miller B, Friedman AJ, Choi H, Hogan J, McCammon JA, et al. (2014) The marine cyanobacterial metabolite gallinamide A is a potent and selective inhibitor of human cathepsin L. J Nat Prod 77: 92-9.

60. McKerrow JH, Doyle PS, Engel JC, Podust LM, Robertson SA, et al. (2009) Two approaches to discovering and developing new drugs for Chagas disease. Mem Inst Oswaldo Cruz 104: 263-9.

61. Vieira DF, Choi JY, Calvet CM, Siqueira-Neto JL, Johnston JB, et al. (2014) Binding mode and potency of N-indolyloxopyridinyl-4-aminopropanyl-based inhibitors targeting Trypanosoma cruzi CYP51. J Med Chem 57: 10162-75.

62. McCall LI, El Aroussi A, Choi JY, Vieira DF, De Muylder G, et al. (2015) Targeting Ergosterol biosynthesis in Leishmania donovani: essentiality of sterol 14 alpha-demethylase. PLoS Negl Trop Dis 9: e0003588.

63. Fonseca NC, da Cruz LF, da Silva Villela F, do Nascimento Pereira GA, de Siqueira-Neto JL, et al. (2015) Synthesis of a sugar-based thiosemicarbazone series and structure-activity relationship versus the parasite cysteine proteases rhodesain, cruzain, and Schistosoma mansoni cathepsin B1. Antimicrob Agents Chemother 59: $2666-77$.

64. Schulze CJ, Donia MS, Siqueira-Neto JL, Ray D, Raskatov JA, et al. (2015) Genome-Directed Lead Discovery: Biosynthesis, Structure Elucidation, and Biological Evaluation of Two Families of Polyene Macrolactams against Trypanosoma brucei. ACS Chem Biol 10: $2373-81$.

65. Ekins S, de Siqueira-Neto JL, McCall LI, Sarker M, Yadav M, et al. (2015) Machine Learning Models and Pathway Genome Data Base for Trypanosoma cruzi Drug Discovery. PLoS Negl Trop Dis 9: e0003878.

66. Jones BD, Tochowicz A, Tang Y, Cameron MD, McCall LI, et al. (2016) Synthesis and Evaluation of Oxyguanidine Analogues of the Cysteine Protease Inhibitor WRR-483 against Cruzain. ACS Med Chem Lett 7: 77-82.

67. Neitz RJ, Chen S, Supek F, Yeh V, Kellar D, et al. (2015) Lead identification to clinical candidate selection: drugs for Chagas disease. J Biomol Screen 20: 101-11. 68. Khare S, Roach SL, Barnes SW, Hoepfner D, Walker JR, et al. (2015) Utilizing Chemical Genomics to Identify Cytochrome b as a Novel Drug Target for Chagas Disease. PLoS Pathog 11: e1005058.

69. Avelar LA, Camilo CD, de Albuquerque S, Fernandes WB, Goncalez C, et al. (2015) Molecular Design, Synthesis and Trypanocidal Activity of Dipeptidyl Nitriles as Cruzain Inhibitors. PLoS Negl Trop Dis 9: e0003916.

70. Ferreira RS, Simeonov A, Jadhav A, Eidam O, Mott BT, et al. (2010) Complementarity between a docking and a high-throughput screen in discovering new cruzain inhibitors. J Med Chem 53: 4891-905.

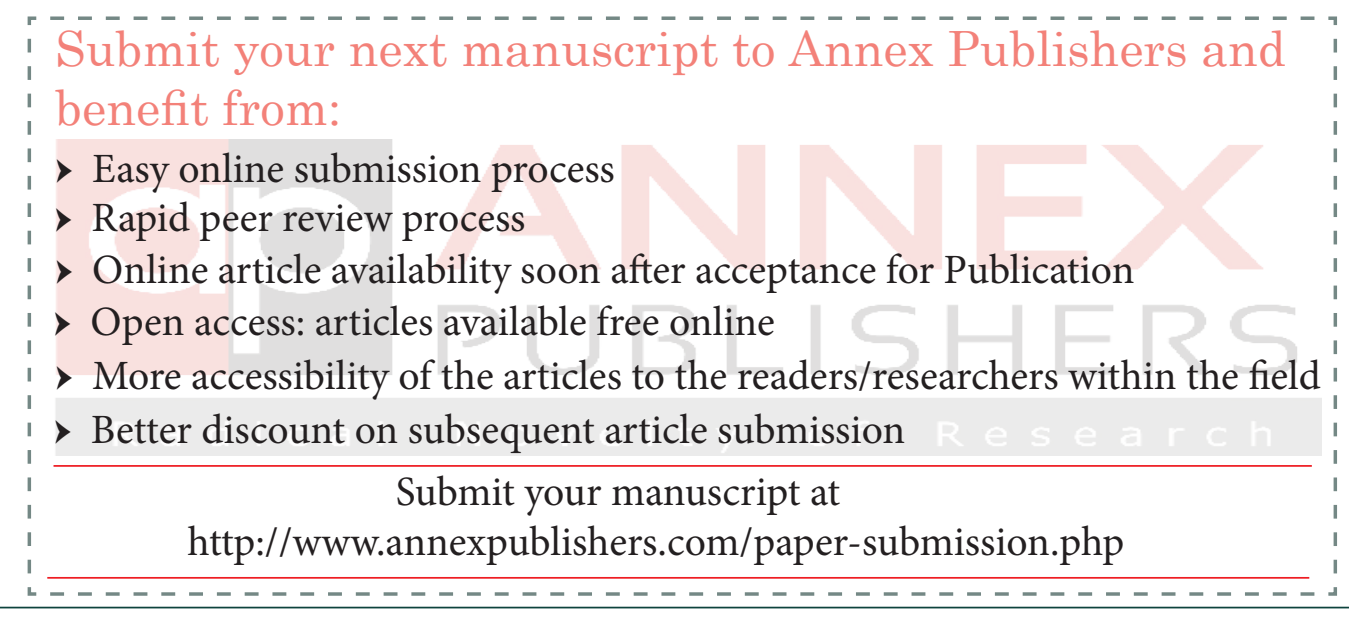

